\section{Dispensing in general practice}

\section{Overhaul system of reimbursement}

EDIToR,-Tony J Morton-Jones and Mike A L Pringle confirm something that most dispensing doctors, medical advisers to family health services authorities, and district pharmacists have known all along-namely, that the present system of reimbursement discourages dispensing doctors from fully using all the generic drugs available.' They are wrong, however, to describe dispensing doctors as "short interval prescribers," portraying them as a burden to their patients in terms of prescription fees. Is not the reverse true in that non-dispensing doctors often give three months' treatment on one script, potentially causing waste and poor compliance? The authors neglect this point in their discussion.

Despite this the paper brings to light problems that must be addressed, and this is no doubt why Lincolnshire Family Health Services Authority sponsored the project. I wish to suggest three solutions, which in combination solve all the problems posed by the paper.

Firstly, the percentage profit should be replaced with an increased dispensing fee per item. The dispensing doctor would not face a financial disincentive to stock cheaper generic drugs and would be compensated for the loss in income.

Secondly, an overhaul of the prescription charges mechanism is long overdue. Charges should relate to the prescription interval. There should be a smaller charge for intervals of less than seven days and cumulative charges for each period of 28 days on one prescription. This would encourage all doctors to prescribe in smaller amounts and be fairer to all patients. It would not be difficult to administer. There are, of course, other issues that need to be included in any review of the system-for example, which chronic diseases merit patients being exempted from charges.

Thirdly, dispensing doctors should be allowed to sell over the counter drugs. This would reduce the number of cheaper items prescribed, avoid patients having to make long journeys to the local town for such drugs, and avoid patients paying prescription charges for cheap drugs just to avoid the inconvenience and cost of travel.

No doubt some people will try to use MortonJones and Pringle's paper as a stick with which to beat dispensing doctors. I believe that with proper interpretation the paper does not injure the principle of doctors dispensing but merely indicates some shortcomings in the system of financial control.

TERRY MCCORMACK

Whitby Group Practice,

Spring Vale Medical Centre,

Whitby,

North Yorkshire YO21 1SD

1 Morton-Jones TJ, Pringle MAL. Prescribing costs in dispensing practices. BMF 1993;306:1244-6. (8 May.)

\section{Criticisms unfounded}

Editor,-Tony J Morton-Jones and Mike A L Pringle have fallen into the trap of not differentiating between dispensing and prescribing costs, thus "proving" to pharmacists and others that dispensing by doctors is a more expensive alternative.'

\section{Advice to authors}

Priority will be given to letters that are less than 400 words long and are typed with double spacing. All authors should sign the letter. Please enclose a stamped addressed envelope for acknowledgment.

The Prescription Pricing Authority-the source of the authors' figures-cannot differentiate between dispensing and non-dispensing patients in a dispensing practice from the bundles of precriptions submitted. All are attributed to the dispensing list, yet many non-dispensing patients - either temporary residents or patients given personally administered items - have their prescriptions dispensed by the doctor. This adversely influences the overall cost of dispensing by doctors but these patients are not included in the number of dispensing patients on the practices' list. In a holiday area such as Lincolnshire the numbers of temporary residents will be considerable.

The choice of just 10 "selected" drugs is far too few for a proper statistical analysis of dispensing costs.

By using crude figures from the Prescription Pricing Authority Morton-Jones and Pringle fail to recognise the effect of value added tax, which is included for scripts dispensed by dispensing doctors but not those dispensed by pharmacies. Calculations based on these figures are bound to be inaccurate in favour of prescribing by nondispensing practices. Value added tax during the study was $15 \%$. Perhaps this is why the average net ingredient cost per patient differed by $13 \%$, to the disadvantage of dispensing doctors.

An important feature for dispensing practitioners is that they pay for the drugs themselves, being reimbursed much later; this leads to more cost conscious prescribing and shorter prescribing intervals. Morton-Jones and Pringle attribute this, without evidence, to the effect of dispensing fees.

To their disadvantage dispensing doctors must dispense all items no matter how cheap, which increases their overall costs. The rurality of their practices leads to increased casualty work in the surgery and more personally administered items, including vaccines, for dispensing and nondispensing patients being passed to the Prescription Pricing Authority and attributed to the dispensing list. Similarly, expensive items are dispensed rather than referred back to the hospital prescriber. $^{2}$

The damaging effect on dispensing general practice of this paper can only be guessed at, but the immediate headlines in the pharmaceutical press $^{34}$ give an inkling, the writers choosing to ignore all the pharmacists' extra fees and assuming that they dispense without cost. Far from it. The average NHS income for each pharmacy in 1990-1 was intended to be $£ 52406 .^{5}$ During the same period, according to the registrar of the Royal Pharmaceutical Society, the average total income of dispensing doctors, including that for general medical services, was just $£ 38412 .^{6}$ Hence my distinction between dispensing costs and drug costs. A non-dispensing doctor's average income was $£ 30676$. In short, the doctor was paid $£ 7736$ against the pharmacist's $£ 52406$ for the same onerous task. Which is the better deal for the NHS?
The myth of extra subsidies for doctors' staff and premises is scotched by the family health services authorities, which now refuse to reimburse these items.

Surely all this deserves consideration in a paper that sets out to compare the costs of the two means of providing patients with their drugs. It is unfortunate that Morton-Jones and Pringle have provided a field day for the detractors of dispensing by doctors.

DAVID ROBERTS

Dispensing Doctors' Association,

Welford,

Northampton NN6 7HG

1 Morton-Jones TJ, Pringle MAL. Prescribing costs in dispensing practices. BMF 1993;306:1244-6. (8 May.)

2 Roberts FD. A case for doctor dispensing. Fournal of the Dispensing Doctors Association 1993;9:14-5.

3 High cost of doctor dispensing. Pharmaceutical fournal 1993;250: cover

4 GP dispensing shown to be a costly option. Chemist and Druggist 1993;239:cover

5 Smith A. The imposed remuneration settlement for community pharmacists 1990-91. Pharmaceutical fournal 1990;245:150 6 Ferguson J. Dispensing and prescribing in the NHS. Pharmaceutical Marketing 1993;4:27.

\section{NHS regulations deny patients cheap drugs}

EDITOR,- In claiming that dispensing doctors are high cost prescribers Tony J Morton-Jones and Mike A L Pringle show little understanding of the issues concerned. ${ }^{12}$ All doctors must dispense, but few are paid by the NHS for it. ${ }^{3}$ Most general practitioners dispense without getting a fee, with the patient taking a prescription to a pharmacy, but there can be no accurate records of the number of prescriptions written. Unlike their metropolitan colleagues, rural dispensing doctors provide a personal, comprehensive 24 hour acute medical service to all their patients, including temporary residents and those on their prescribing lists. Thus although dispensing by doctors seems to cost the NHS more, this may be for services frequently provided by other sectors of the NHS in urban areas. $^{24}$

The government has proposed several measures to save the exchequer considerable sums of money, but they have considerable implications for the patients of all general practitioners working in the NHS: fewer patients will be entitled to free prescriptions; fewer preparations will be available from the NHS; the NHS prescription charge has risen by over $13 \%$ to $£ 4.25$; and many more powerful and more dangerous preparations will be available over the counter, with far less control than there is over the sale of alcohol.

The Medicines Act divides medicines into three categories: those that anyone may sell, those that only a doctor or chemist may sell (the "P" list), and those that may be supplied by a doctor or a pharmacist but only on the instructions of a doctor (prescription only medicines). As no general practitioner may mix NHS and private practice, however, a dispensing doctor must charge an NHS patient $£ 4.25$ for a bottle of aspirin or morphine tablets while being entitled to sell the same to private patients for under $25 \mathrm{p}$.

Clearly, NHS patients are now often charged excessively for prescription only medicines not available from a chemist. ${ }^{2}$ Perhaps the government and NHS fundholders might consider the major benefits of relaxing the NHS dispensing regulations to allow for direct sale of medicines to NHS 
patients-a service currently available only to private patients but that generates income from value added tax.

PAUL THOMAS

Dispensing Doctors' Association,

Gipping Valley Practice,

Barham,

Ipswich 1P6 0AS

1 Morton-Jones TJ, Pringle MAL. Prescribing costs in dispensing practices. $B M F$ 1993;306:1244-6. (8 May.)

2 Thomas PD. Dispensing doctors. BMF 1992;305:650

3 Thomas PD. Dispensing doctors. BMF 1992;305:650.

3 Thomas PD. Payment for drugs. $B M \mathcal{F} 1991 ; 303: 858$.
4 Janowski RF, Mandalia S. Comparison of attendance and

emergency admission patterns at accident and emergency departments in and out of London. BMF 1993;306:1241-3. (8 May.)

\section{Dispensing improves compliance}

EdrTor,-Tony J Morton-Jones and Mike A L Pringle draw attention to the difference in the costs of dispensing by doctors and pharmacies.' They highlight the need for further study of the use of brand name generic drugs. They fail to address two further aspects known to distort the comparison between dispensing and prescribing doctorsnamely, dispensing to temporary residents and compliance. They also do not differentiate between a prescription prescribed and a prescription dispensed.

Virtually all prescriptions written by a dispensing doctor are dispensed. There is evidence that as many as $30 \%$ of prescriptions issued to nondispensing patients are never dispensed.

The authors take no account of the difference in quality of service or patients' satisfaction, or indeed of any outcome of the prescribing or dispensing episode.

The study shows the success of the incentives that support the government's preference for prescribing intervals of not more than 28 days. There are sound clinical grounds for such policy. Greater compliance is achieved and waste reduced. If all long term drugs were prescribed in multiples of 28 day treatments the waste associated with mixed 28 and 30 day prescriptions, which amounts to a $6.67 \%$ difference, could be reduced.

The paper leads to the conclusion that the fact that they prescribe fewer generic drugs is a major factor in the higher costs of dispensing doctors, but other factors need to be evaluated further.

GARETH EMRYS-JONES

Rural Practice Subcommittee,

General Medical Services Committee,

St Columb Major,

Cornwall TR9 6BX

1 Morton-Jones TJ, Pringle MAL. Prescribing costs in dispensing practices. $B M^{7}$ 1993;306: 1244-6. (8 May.)

\section{Short term prescribing not driven by money}

EDITOR,-I take exception to the statement by Tony J Morton-Jones and Mike A L Pringle that there is no risk of product liability for a dispensing medical practice if it accurately records batch numbers and manufacturers of products.' My practice, in common with several others in the east midlands, has used three major drug wholesalers in the past two years. Of the three, one is still in business, one is bankrupt, and the other stopped trading, with its foreign owner going bankrupt a month later. For "own brand" generic drugs from the two bankrupt firms the doctors in my practice are now the only people who can be identified and, if necessary, sued as suppliers. Little wonder that we prefer proprietary brands if possible.

I am also sorry to note that Morton-Jones and Pringle believe that dispensing doctors issue scripts for a shorter period specifically for a financial incentive. Might not these doctors in fact wish to limit the amount of drugs issued at one time and in general keep a tighter control of their prescribing habits? This view is supported by the authors' findings that prescribing doctors in practices with both dispensing and non-dispensing patients follows the same pattern for both groups of patients. There are, of course, doctors who issue large and perhaps dangerous quantities of drugs regularly. I suspect that differences among doctors in frequency and size of prescriptions may be more to do with standards of practice than finance.

Morton-Jones and Pringle have thrown important new light on issues affecting prescribing costs. It would be unfortunate if those who control budgets concluded that the issues were now settled; there may be other subtle influences yet to be identified.

Sleaford Medical Group,

Riverside Surgery,

Sleaford,

Lincolnshire NG34 7HD

1 Morton-Jones TJ, Pringle MAL. Prescribing costs in dispensing practices. $B M F$ 1993;306:1244-6. (8 May.)

\section{Legal pitfalls with generic prescribing}

EDITOR,-Lincolnshire Local Medical Committee considered Tony J Morton-Jones and Mike A L Pringle's paper ${ }^{1}$ when it was presented in its original form as a report to Lincolnshire Family Health Services Authority. The local medical committee considered that the problems associated with product liability were the main reason behind the difference in prescribing habits of dispensing and prescribing doctors in the county. The profession has been told by the General Medical Services Committee and the protection societies that all doctors, and especially dispensing doctors, should be aware of the problems of product liability, particularly as they apply to generic medicines, and that they should take steps to protect themselves against the effects of the legislation. The general effect of this advice has been to lower the proportion of generic drugs prescribed by dispensing doctors.

In their original report the authors gave scant regard to the question of product liability, and it is encouraging that the published paper addresses this problem more fully. The solution proferred, however-that keeping details of batch numbers etc protects against possible litigation-is not entirely correct as in Lincolnshire recently two suppliers of generic medicines have gone into liquidation; under these circumstances the dispensing doctor assumes full product liability. Lincolnshire Local Medical Committee though that, as worries about product liability were the chief factor keeping dispensing doctors' costs higher than those of prescribing colleagues, the matter could be resolved by a family health services authority or, indeed, the Department of Health taking out indemnity against damages arising from legal proceedings under the legislation concerning product liability.

If the concerns about product liability are as small as the authors make out, the cost of such an indemnity would be minimal compared with the savings that would be generated by an increase in generic prescribing as shown in the paper.

DAVID SMITH

Lincolnshire Local Medical Committee,

Surgery,

Swineshead

Boston,

Lincolnshire

1 Morton-Jones TJ, Pringle MAL. Prescribing costs in dispensing practices. BMF 1993;306:1244-6. (8 May.)

\section{Authors' reply}

EDrTor,-The argument concerning value added tax (VAT) raised by David Roberts and Paul Thomas is incorrect. We used net ingredient costs in our analysis from PD2 returns supplied by the
Prescription Pricing Authority to family health services authorities. Net ingredient costs are the basic cost of the drug or appliance-that is, the total cost minus container allowance, fees, on cost allowance, discounts, and VAT. The fact that we eliminated VAT from our analysis highlights the dangers in drawing conclusions from two similar figures, as Roberts does with the level of VAT and the difference in the net ingredient cost per patient.

Roberts also comments on our choice of just 10 drugs as being too few for a proper statistical analysis. In fact, we used the 10 drugs only to show differences in prescribed quantities between dispensing and non-dispensing patients, the main analysis being done on the basis of the data from the Prescription Pricing Authority.

There are indeed many temporary residents in Lincolnshire, mainly concentrated around the coastal towns. The argument, however, that temporary residents have a role in explaining dispensing practices' high costs relies on the relative numbers of such residents among the dispensing and non-dispensing practices rather than the overall numbers. In fact, the practices in the seaside towns are predominantly nondispensing practices, which implies that most temporary residents register with non-dispensing practices, thus more than compensating for those who register with dispensing doctors.

Roberts raises the issue of rurality. There is no evidence to support this speculation, and indeed our analysis shows that rurality is ineffective in explaining the differences in costs between dispensing and non-dispensing practices. J Deane Collinge states that the shorter prescribing intervals are possibly due to dispensing doctors keeping a tighter control of their prescribing habits. Our findings, however, do not support this view as claimed. In fact, the average number of items prescribed per dispensing patient is 9.93 compared with 9.09 per non-dispensing patient in dispensing practices. If Collinge's argument is valid these two figures would be expected to be similar.

In our study we merely wished to compare the prescribing levels, costs, and habits of dispensing and non-dispensing practices, and we were emphatically not making a case for the abolition of dispensing practices. If such a case were to be made it would, as two authors note, require an examination of the quality and cost effectiveness of dispensing practices compared with pharmacies.

Perhaps the most important point raised, however, is that of product liability. We appreciate that this is probably more complicated than we suggested in the paper, especially with respect to suppliers ceasing to trade. We fully support suggestions such as that of David Smith for central indemnity for product liability. This is obviously the best way forward, and if such a scheme was introduced we would expect a concomitant rise in generic prescribing and fall in prescribing costs of dispensing doctors. As one of us is a partner in a dispensing practice we hope that the future of dispensing practices will not be jeopardised by differences in the prescribing costs between dispensing and non-dispensing practices.

MIKE PRINGLE TONY MORTON-JONES

Department of General Practice,

Queen's Medical Centre,

Nottingham NG7 2UH

\section{Teenage pregnancy}

\section{Give girls a motive for avoiding it}

EDITOR,-Trevor Smith's paper shows that a higher proportion of young girls from deprived backgrounds become pregnant than girls from affluent backgrounds but a higher proportion of the girls from affluent backgrounds obtain 